\title{
The Improvement of Mental Rotation Performance in Second Graders after Creative Dance Training
}

\author{
Petra Jansen*, Jan Kellner, Cornelia Rieder \\ Institute of Sport Science, University of Regensburg, Regensburg, Germany \\ Email: "petra.jansen@psk.uni-regensburg.de
}

Received November $8^{\text {th }}, 2012$; revised April $28^{\text {th }}, 2013$; accepted May $9^{\text {th }}, 2013$

\begin{abstract}
Copyright $(\underset{2}{ } 2013$ Petra Jansen et al. This is an open access article distributed under the Creative Commons Attribution License, which permits unrestricted use, distribution, and reproduction in any medium, provided the original work is properly cited.
\end{abstract}

\begin{abstract}
The study presented here investigated the influence of creative dance training on mental rotation performance. Two groups of second graders solved a paper-pencil mental rotation test and a motor performance test. Afterwards one group received five weeks of normal physical education lessons, while the other group received five weeks of creative dance training. At the end of the training period all children solved the mental rotation again. The results show that the dance-training group improved their mental rotation performance more than the physical education group. Further studies should investigate whether this positive effect of creative dance training transfers to cognitive, social, and emotional skills, such as a possible enhancement of self-esteem.
\end{abstract}

Keywords: Mental Rotation; School-Aged Children; Motor Performance; Creative Dance; Regular Sports Class

\section{Introduction}

Due to the decreasing motor abilities of children in the last few years on the one hand and the increasing pressure to perform well in the educational system on the other hand, it becomes more and more important to comprehend the relationship between motor abilities and cognitive performance. This study concentrates on the effect of creative dance training on one specific visual-spatial performance task, namely mental rotation, which describes the ability to imagine how an object would appear when it is rotated from its actual presented orientation (Shepard \& Metzler, 1971). Mental rotation serves an important role in science, and some work contexts, for example, for pilots (Dror, Kosslyn, \& Waag, 1993). Furthermore, it is also a relevant factor for mathematical learning (Hegarty \& Kozhehvnikov, 1999). Because in dance-training, orientation in space and spatial awareness are two of the main cognitive abilities (Bläsing \& Schack, 2012), a positive influence of dance training on mental rotation is expected.

Currently there are some studies, with different methodological designs, which already show a relationship between motor performance and mental rotation performance. A correlation analysis by Jansen and Heil (2010) showed that motor abilities and mental rotation performance do correlate even while general intelligence was controlled (Jansen \& Heil, 2010). In studies with quasi-experimental designs, it was investigated whether children who showed motor disabilities also have impaired mental rotation performance. This assumption was confirmed in studies with children with spina bifida (Wiedenbauer \& Jansen-Osmann, 2007) and overweight children (Jansen et al., 2010). Spina bifida is a neural defect caused by an incomplete

"Corresponding author. closure of the embryonic neural tube during the first month of embryonic development. The consequences of this can be paralysis and loss of sensation below the spinal cord defect. The severity of the symptoms depends on the defect's location. For this, children with spina bifida are unable to move with out help. Being overweight was determined by the Body Mass Index according to reference data and it was already shown that overweight children show an impaired motor performance (Graf et al., 2004).

Experimental designs can be further differentiated by the use of interference paradigms or training programs. One prominent study with an interference design is the study of Wexler, Kosslyn and Berthoz (1998) who showed that if the direction of a mental and a simultaneous conducted manual rotation were not compatible, reaction times were slower and more errors occurred than if the directions of both rotations were compatible with each other. This interference effect was confirmed in a study with children at the ages of 5,8 , and 11 years old and adults. The effect was demonstrated in the two groups of younger children, but it was not found in the 11 years old children and not in adults (Frick, Daum, Walser, \& Mast, 2009). In training studies, it has been shown, that the mental rotation performance could be improved by manual rotation training (Wiedenbauer \& Jansen-Osmann, 2008). Two groups of tenyear old children received computer training for one hour. The experimental group used a joystick to rotate objects on a computer screen, while the control group solved a non-spatial computer game. The improvement in the mental rotation performance from the pre- to the posttest was much higher for the manual rotation group than for the control group. This result was confirmed in a study with adults (Jansen, Titze, \& Heil, 2009) and children (Jansen, Lange, \& Heil, 2011) who learned to 
juggle for a period of three months.

In none of the training studies mentioned above, the influence of dance training on mental rotation performance is investigated. Up to now, there are no studies with children, yet there are studies with older people investigating the influence of dance training on cognitive performance (Coubard Duretz, Lefebvre, Lapalus, \& Ferrufino, 2011; Kattenstroth, Kolankowska, Kalisch, \& Dinse 2010) but not particularly mental rotation. Keinänen, Hetland and Winner (2000) investigated whether dancing leads to enhanced academic skills in two small meta-analyses. Their results suggest that dance instruction improves visual-spatial skills. Due to the spatial components in dance, the training of orientation and spatial awareness, a positive training influence of dance training on mental rotation performance in second graders is supposed. Furthermore, it can be assumed that dance training enhances motor ability in schoolaged children.

\section{Material \& Methods}

\section{Participants}

Sixty-five second grade pupils ( 31 girls and 34 boys) participated in this study. The children were between 7 and 9 years old (mean age: 7.68 years, $S D=.503$ ) and were recruited from a primary school in Bavaria, Germany. Because the children were tested in their school context, two classes (44 children, 20 girls and 24 boys) were randomly assigned to the experimental group (EG), who received dance training. One class, (21 children, 11 girls and 10 boys), was assigned to the control group (CG), and took part in the normal physical education at school. Parents gave written informed consent and data was collected anonymously.

\section{Measures}

A mental rotation test (PMRT), a motor ability test (Movement Assessment Battery, M-ABC-2), and a test of cognitive speed (ZVT) were used. All tests will be described in detail here.

\section{Picture Mental Rotation Test (PMRT, Neuburger, Jansen, Heil, \& Quaiser-Pohl, 2011)}

The Picture Mental Rotations Test is a paper pencil mental rotation test and we included one set of animal pictures as stimuli. Each row is comprised of one target item on the left side and four sample items on the right side. Two of the four items on the right side were correct, meaning identical but picture plane rotated versions of the target item on the left side $\left(45^{\circ}\right.$, $90^{\circ}, 135^{\circ}$, or $225^{\circ}$ rotated compared to target item). The other two items were incorrect, which means that they were mirror images of the target item (see Figure 1). The children's task was to cross out the two correct items on the right side within a time limit of three minutes for the 16 rows. There were two
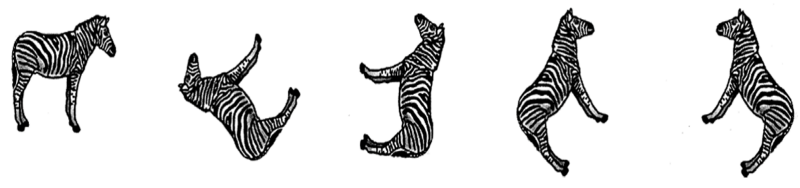

Figure 1.

Example item of the mental rotation test. items provided as examples and two items for practice that were reviewed before the test began. Rotation performance was defined as the number of correctly solved items in the MRT.

\section{Movement Assessment Battery for Children, (M-ABC-2, Petermann, 2009)}

The Movement-ABC-2 was used to control for motor advantages or deficits in the children. It consists of eight motor tasks divided in the following categories: manual dexterity (3 tasks), ball skills ( 2 tasks), and static and dynamic balance ( 3 tasks). The results were analyzed for each task and a total score was computed. The inter-rater-reliability for the $\mathrm{M}-\mathrm{ABC}$ is .95 and the retest-reliability is .95 .

\section{Number Connection Test, (ZVT, Oswald \& Roth, 1982)}

The ZVT is a measurement of cognitive speed and is related to intelligence measurements, with a correlation of $r=.60$ to .80 (Vernon, 1993). All values could be transformed in IQ-values. This test consists of four sheets of paper. On each sheet, the numbers 1 to 90 are presented in a scrambled order in a matrix of 9 rows and 10 columns. The children must connect the numbers as fast as possible in ascending order with a pen in a time slot of 60 seconds per sheet. The number of correctly connected numbers was analyzed for each participant. The test-retest reliability (six month) of the ZVT reads about .90 to .95 . The ZVT is the equivalent to the Trail Making Test A (Reitan, 1956). The test administration, including instructions and practice matrices, takes about 20 minutes.

\section{Intervention}

Dance training as creative dance training was taught in five sessions. Each week a new theme was developed and matched with the appropriate music. The idea of creative dance for children is to activate the body as well as the mind through dance and music. The children are guided to express their own personality and create their own composition while telling a story or reacting a scene through dance instead of simply rehearsing a distinct choreography. Every unit started with a short warm up where the children were instructed to use different movement styles like e.g. robot, disco queen, crazy opera singer, or marionette. The themes developed in the five weeks of training were below.

\section{Magic House Task}

Children had to imagine that they move through different rooms in a house, and they had to transform into a different animal in each different room. Then they were allowed to move like this specific animal and simulate waking up, a possible hibernation, falling asleep etc.

\section{Weather Task}

Children had to represent different weather situations.

\section{Cowboy's and Indian's Task}

Children should develop a short story plot with Cowboys and Indians. First, the Cowboys and Indians fight with each other and later dance together. Big city task: Children had to embody the awakening of a big city and act like different characters typically found in big cities like bus drivers, policemen, homeless people, businessmen, etc. These characters were named to 
the children.

\section{Round the World Task}

Children were flying around the world (imitate airplanes) with stops in different countries imitating different nationalities through their dance styles (USA-High Five, Russia-Kazachok, Japan-make a bow, Austria-"Schuhplattler" (an Austrian folkdance), Home-clapping game).

Children in the control group took part in the normal physical education during the five weeks with the constraint that no dancing or physical lessons with a lot of rotational movements and gymnastics were performed. For that reason children had lessons in track and field and ball games. In these lessons they learned to throw and catch balls and to play with each other games with rules.

\section{Procedure}

Children were tested in a multipurpose room (M-ABC-2) and in their classroom (PMRT and ZVT) during regular school time before two-week holidays. After a short introduction, children had to complete the M-ABC-2 in groups of 8. After a short break children had to solve the PMRT and then the ZVT all together in their class-room. Training started in the week following the vacation and went on for five weeks. The training was conducted three times a week for 45 minutes. The experimental group received specific dance training (see description above). The control group took part in the normal physical education lessons in school. These lessons took part also three times a week for 45 minutes. The mental rotation performance of all children was tested again in the week following the last week of training.

\section{Analysis}

First, two different univariate analysis of variance were conducted with 1) the cognitive speed measurements score and 2) the total score of the M-ABC-2 as dependent variables and the independent variables "group" (experimental group, control group) and "gender" (female, male).

Second, one analysis of variance was conducted with the dependent variable and "mental rotation difference" which are defined as the difference between the pre- and post test in mental rotation performance. The independent variables were the factor, "group" (experimental group, control group), and the factor, "gender" (male, female). Because of the well-documented gender differences in the MRT psychometrical mental rotation test (Neuburger et al., 2011), gender was chosen as a separate factor.

Third, a correlation analysis was calculated between mental rotation performance, IQ score, and $\mathrm{M}-\mathrm{ABC}-2$ scores. For this, the pretest data were used. Due to multiple testing in the correlation analyses the significance level was corrected by the Bonferroni method and the level of $p \leq .01$ was considered significant.

\section{Results}

\section{Analyses of Variance}

\section{Cognitive Processing Speed}

There was no main effect of "group", $\mathrm{F}(1,61)=.65$, n.s., and of "gender", $F(1,61)=.08$, n.s. and no interaction between both
Table 1.

Mean (standard deviation) of cognitive processing speed and motor performance dependent on gender and group.

\begin{tabular}{cccc}
\hline & & $\begin{array}{c}\text { Cognitive } \\
\text { Processing Speed } \\
\text { (IQ-value })\end{array}$ & $\begin{array}{c}\text { Motor } \\
\text { performance } \\
(\text { M-ABC-score })\end{array}$ \\
\hline $\begin{array}{c}\text { Experimental } \\
\text { Group }\end{array}$ & $\begin{array}{c}\text { Female } \\
(\mathrm{N}=20)\end{array}$ & $104.35(8.76)$ & $63.08(25.28)$ \\
& $\begin{array}{l}\text { Male } \\
(\mathrm{N}=24)\end{array}$ & $103.83(11.79)$ & $63.52(28.81)$ \\
& $\begin{array}{c}\text { Female } \\
(\mathrm{N}=11)\end{array}$ & $107.18(10.14)$ & $80.18(25.25)$ \\
Control Group & $\begin{array}{l}\text { Male } \\
(\mathrm{N}=10)\end{array}$ & $105.9(15.82)$ & $62.3(25.15)$ \\
\hline
\end{tabular}

factors, $\mathrm{F}(1,61)=.016$, n.s. (see Table 1).

\section{Motor Performance}

There was no main effect of "group", $F(1,61)=1.5$, n.s., and of "gender", $F(1,61)=1.21$, n.s. and no interaction between both factors, $F(1,63)=1.55$ n.s., in the overall motor performance score (see Table 1).

\section{Effect of Training on Mental Rotation Performance}

There was only a significant main effect of "group", $F(1,61)$ $=5.14, p<.05, \eta^{2}=.08$, but not of "gender", $\mathrm{F}(1,61)=.93$, n.s., and no significant interaction between both factors $F(1,61)=$ 1.63 , n.s., in the difference score in mental difference. The difference between the pre- and posttest was higher for the children in the experimental group (EG) compared to the children in the control group (CG) (EG: $\mathrm{M}=3.58, \mathrm{SE}=.46$; $\mathrm{CG}$ : $\mathrm{M}=$ $1.71, \mathrm{SE}=.68)$. The $\mathrm{EG}$ and the $\mathrm{CG}$ did not differ in their mental rotation performance in the pre-test, $\mathrm{F}(1,62)=1.84$, n.s. The results are presented in Figure 2.

\section{Correlational Analyses}

Mental rotation performance was correlated with intelligence $(\mathrm{r}=.384, p<.001)$ and with certain dimensions of the Movement-ABC-2, namely with hand dexterity $(\mathrm{r}=.297, p<.01)$ and the overall motor score $(\mathrm{r}=.262, p<.01)$. Mental rotation did not correlate with balance or ball tasks. The bivariate correlations, however, do not permit us to determine whether or not motor development can predict significant additional variance of mental rotation performance over and above individual differences in intelligence.

\section{Regression Analysis}

The stepwise multiple regression results (see Table 2) show that only $13.9 \%$ of the variance $(\mathrm{R} 2=.147)$ is explained by the predictor cognitive speed, $\mathrm{F}(1,102)=17.47, p<.001$.

\section{Discussion}

This experiment showed that mental rotation performance could be improved in a school context by physical education lessons and creative dance training, whereby the improvement was higher for the creative dance training compared to physical education lessons. The higher improvement of the EG could not 


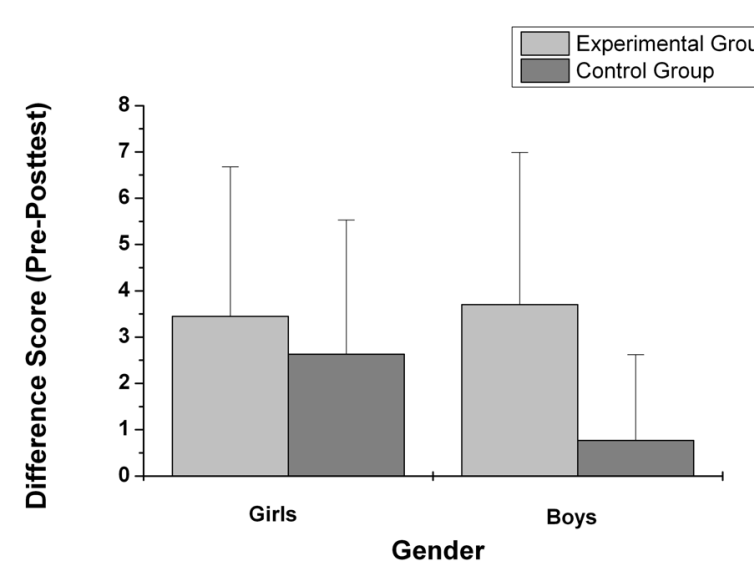

Figure 2.

Difference score (mean and standard deviation) between pre- and posttest on mental rotation dependent on gender and group.

Table 2.

Stepwise multiple regression model for the mental rotation performance based on the following predictors: gender, hand dexterity, motor score and cognitive processing speed (IQ).

\begin{tabular}{ccccc}
\hline Predictor & $\begin{array}{c}\text { Regression } \\
\text { coefficient }\end{array}$ & $\beta$ & $\mathrm{T}$ & $p$ \\
\hline $\begin{array}{c}\text { Cognitive } \\
\text { processing speed }\end{array}$ & .150 & .384 & 4.180 & $<.001$ \\
Hand dexterity & & .178 & 1.815 & $>.05$ \\
$\quad$ Gender & & 103 & 1.121 & $>.2$ \\
Total motor score & & .129 & 1.258 & $>.2$ \\
\hline
\end{tabular}

be explained by each group receiving different levels of attention, because the children of the EG and the ones of the CG both knew that they participated in an experiment and the trainings were equivalent in time. Because the dance training required spatial orientation and rotation around the body axes, the higher improvement of the dance-training group compared to the control group, who did not receive orientation or rotational training could be attributed to the kind of training each group received. This result is in line with a quasi-experimental study of Steggemann, Engbert and Weigelt (2011), who showed that rotational movement experts had a better mental rotation performance, even though this result appeared only with perspective transformations and not with object based mental rotations. Both groups in the current study did not differ in their speed of cognitive processing and their overall motor performance, so we can conclude that the positive result of the dance training could not be attributed to a possible cognitive processing speed difference.

The regression analysis showed that only a small amount of variance could be explained by the measurement, of speed of cognitive processing, but not by motor ability. This is in contrast to the correlational analysis of Jansen and Heil (2010). They showed in a study with preschool children that two items of a specific motor test, the MOT 4 - 6, "collecting sticks bimanually" and "winding through a hoop without touching the hoop" predict mental rotation performance even while including an intelligence measurement in the regression analysis. Both studies differ in many factors, as for example the mental rotation test used, the motor- and intelligence measurement, and the age of the children. It is quite astonishing that the mental rotation performance could not be strongly predicted in this study by intelligence or motor abilities. Other variables, not investigated in this study, seem to play an important role explaining the mental rotation performance when using embodied stimuli, such as emotional processing and working memory. Mammarella (2011) showed an increase in mental rotation abilities after unconscious visual processing of emotional expressions. While the influence of emotions has only been demonstrated for embodied stimuli, it may also be a factor for non-embodied stimuli, as for example abstract cube figues. According to this, emotional processes should be considered in further analysis of mental rotation as well as working memory processes. The importance of working memory processes during mental rotation was shown in several neuroscientific studies by e.g. Anguera, Reuter-Lorenz, Willingham and Seidler (2009) and Jordan, Heinze, Lutz, Kanowski and Jäncke (2001). At this point behavioral studies which are missing to investigate the relationship between mental rotation- and working has shown that creative dance training improved mental rotation performance more than the "normal" physical education lessons. Dance is an activity that generally refers to movement of the body, usually rhythmic, to music and is used as a form of expression and social interaction. Because dance involves so many different aspects, e.g. motor, cognitive, and social ones, it is not astonishing that dance has this enhancing effect on mental rotation ability.

In addition to the cognitive effects of the creative dance training, the training effect on motor abilities has to be considered in further studies. There are some studies with patients with Parkinson Disease, which show that dance training can improve their motor deficit symptoms (Hackney \& Earhart, 2009, 2010). Due to this promising result the effect of dance training on specific motor tasks, as for example balance, has to be investigated in more detail.

To conclude, this study gives support to the assumption that dance training can enhance mental rotation performance and that this kind of training is more effective for this improvement than normal physical education lessons. In further studies it has to be investigated if this effect transfers to cognitive, social, and emotional skills, such as a possible enhancement of self-esteem. In addition, it should be explored in more detail why dance especially has such a positive impact on mental rotation skills. To summarize, while more research is clearly needed, the study suggests that creative dance training improves cognitive skills.

\section{REFERENCES}

Anguera, J. A., Reuter-Lorenz, P. A., Willingham, D. T., \& Seidler, R. D. (2009). Contributions of spatial working memory to visuomotor learning. Journal of Neuroscience, 22, 1917-1930.

Bläsing, B., \& Schack, T. (2012) Mental representation of spatial movement parameters in dance. Spatial Cognition \& Computation, 12 , 111-132. doi:10.1080/13875868.2011.626095

Coubard, O. A., Duretz, S., Lefebvre, V., Lapalus, P., \& Ferrufino, P. Practice of contemporary dance improves cognitive flexibility in aging. Frontiers in Aging Neuroscience, 3, 1-12.

Dror, I. E., Kosslyn, S. M., \& Waag, W. L. (1993). Visual-spatial abilities of pilots. Journal of Applied Psychology, 78, 763-773. doi:10.1037/0021-9010.78.5.763

Frick, A., Daum, M. M., Walser, S., \& Mast, F. (2009). Motor processes in children's mental rotation. Journal of Cognition and Development, 10, 18-40. doi:10.1080/15248370902966719 
Graf, C., Koch, B., Dordel, S., Schindler-Marlow, S., Icks, A., Schüller, A., Bjarnason-Wehrens, B., Tokarski, W., \& Predel H. (2004). Physical activity, leisure habits and obesity in first-grade children. European Journal of Cardiovascular Prevention and Rehabilitation: Official Journal of the European Society of Cardiology, Working Groups on Epidemiology \& Prevention and Cardiac Rehabilitation and Exercise Physiology, 11, 284-290

Hackney, M. E., \& Earhart, G. M. (2010). Effects of dance on gait and balance in Parkinson's disease: A comparison of partnered and nonpartnered dance movement. Neurorehailitation Neural Research, 24, 384-392. doi: $10.1177 / 1545968309353329$

Hackney, M. E., \& Earhart, G. M. (2010). Effects of dance on balance and gait in severe Parkinson disease: A case study. Disability Rehabilitation, 32, 679-684. doi:10.3109/09638280903247905.

Hegarty, M., \& Kozhevnikov, M. (1999). Types of visual-spatial representations and mathematical problem solving. Journal of Educational Psychology, 91, 684-689. doi:10.1037/0022-0663.91.4.684

Jansen, P., \& Heil M. (2010). The relation between motor development and mental rotation ability in 5- to 6-year-old children. European Journal of Developmental Science, 4, 66-74.

Jansen, P., Lange, L., \& Heil, M. (2011). The influence of juggling on mental rotation performance in children. Biomedical Human Kinetics, 3, 18-22. doi:10.2478/v10101-011-0005-6

Jansen, P., Schmelter, A., Kasten, L., \& Heil M. (2011). Impaired mental rotation performance in overweight children. Appetite, 56, 766769. doi:10.1016/j.appet.2011.02.021

Jansen, P., Titze, C., \& Heil, M. (2009). The influence of juggling on mental rotation performance. International Journal of Sport Psychology, 40, 351-359.

Jordan, K., Heinze, H.-J., Lutz, K., Kanowski, M., \& Jäncke, L. (2001). Cortical activations during the mental rotation of different visual objects. NeuroImage, 13, 143-152. doi:10.1006/nimg.2000.0677

Kattenstroth, J. C., Kolankowska, I., Kalisch, T., \& Dinse, H. (2010). Superior sensory, motor, and cognitive performance in elderly individuals with multi-year dancing activity. Frontiers in Aging Neuroscience, 2, 1-9.

Keinanen, M., Hetland, L., \& Winner, E. (2000). Teaching cognitive skills through dance: Evidence for near but not far transfer. Journal of Aesthetic Education, 34, 295-306. doi:10.2307/3333646

Mammarella, N. (2011). Is there a "special relationship" between unconscious emotions and visual imagery? Evidence from a mental rotation test. Consciousness and Cognition, 20, 444-448. doi:10.1016/j.concog.2010.10.012

Neuburger, S., Jansen, P., Heil, M., \& Quaiser-Pohl, C. (2011). Gender differences in pre-adolescents' mental rotation performance: Do they depend on grade and stimuli? Personality and Individual Differences, 50, 1238-1242. doi:10.1016/j.paid.2011.02.017

Oswald, W. D., \& Roth, E. (1987). Der Zahlen-Verbindungs-Test ZVT. Göttingen: Hogrefe.

Petermann, F. (2009). Movement Assessment Battery for Children-2 (M-ABC-2) (2.veränd. Auflage). Frankfurt am Main, Pearson Assessment: Hrsg.

Reitan, R. M. (1956). Trail making test. Manual for administration, scoring, and interpretation. Indianapolis, IN: Indiana University Press.

Shepard, R. N., \& Metzler, J. (1971). Mental rotation of three-dimensional objects. Science, 171, 701-703.

doi:10.1126/science.171.3972.701

Steggemann, Y., Engbert, K., \& Weigelt, M.(2011). Selective effects of motor expertise in mental body rotation tasks: Comparing objectbased and perspective transformations. Brain and Cognition, 76, 97105. doi:10.1016/j.bandc.2011.02.013

Vernon, P. A. (1993). Der Zahlen-Verbindungstest and other trailmaking correlate of general intelligence. Personality and Individual Differences, 14, 35-40. doi:10.1016/0191-8869(93)90172-Y

Wexler, M., Kosslyn, S. M., \& Bertholz, A. (1998). Motor processes in mental rotation. Cognition, 68, 77-94. doi:10.1016/S0010-0277(98)00032-8

Wiedenbauer, G., \& Jansen-Osmann, P. (2007). Mental rotation ability of children with spina bifida: What influence does manual rotation training have? Developmental Neuropsychology, 32, 809-824. doi:10.1080/87565640701539626

Wiedenbauer, G., \& Jansen-Osmann, P. (2008). Manual training of mental rotation in children. Learning and Instruction, 18, 30-41. doi:10.1016/j.learninstruc.2006.09.009 